\title{
2
}

\section{Making effective participatory environmental health science through collaborative data analysis}

\author{
Barbara L. Allen
}

\section{Introduction}

Recent politics has amplified, albeit in stark terms, some simmering issues with the frame of participatory science. For example, when claims of environmental injustice are raised, citizen groups often produce a different set of data from that used by industry or the state to back up their assertions - "alternative facts," if you will, to borrow a term from the contemporary political arena. This is part of epistemic modernization (Hess 2007; Moore et al. 2011) or epistemic democratization (Sismondo 2017) whereby laypeople and social movement groups participate in shaping the science and enacting the scientific agendas that impact them (Hess 2015; Hess et al. 2017). However, as I will argue in this chapter, the kinds of new knowledge that residents of environmentally compromised communities produce, while different from the science they are arguing against, are substantively and categorically opposite from the popular press version of "alt facts" in our post-truth era. By this I refer to the recent right-wing political demagoguery, bent on "inflaming anger and resentment" (Hoffman 2018, 449 ) and willing to invent and disseminate new "facts" as needed for coercion and confusion in the name of proto-authoritarian political gamesmanship. This so-called populism is not the same as public participation in the creation of science, which involves "arrangements that facilitate the active involvement of 
outsiders" (Marres 2018b, 454) toward a rich and reflexive "knowledge democracy" (Marres 2018a). Before discussing the ways in which relevant and rigorous alternative science is produced by residents in contested regions, it would be helpful to explain what exactly constitutes participatory or citizen science today.

Dividing citizen science into a four-level classification scheme, Alan Irwin (2015, citing Haklay 2013) has attempted to link participation to depth of engagement with making scientific knowledge. Level 1 citizen science covers crowdsourcing and other activities that engage citizens in gathering specific kinds of information such as wildlife counting and other types of empirical data gathering for expert-devised projects. "Distributed intelligence" defines level 2 citizen science, where laypeople are interpreting scientific issues prepackaged by experts such as citizen juries and consensus conferences. Level 3 citizen science is termed "participatory science," defined as lay inclusion in both problem definition and data collection. This could include some forms of popular epidemiology and resident-initiated data collection such as water and air sampling to expose contamination. The final classification, level 4 citizen science, Haklay calls "extreme" participation in science, but I will call it "strongly participatory" science following Harding's concept of "strong objectivity" (Harding 1991, 2015). Strongly participatory science is knowledge-making that is collaborative all the way down - from the problem definition, methodological considerations and data collection, to the final analyses (Allen 2018). What "demarcates citizen science activities (of whatever sort) from more conventional science is that they build not only on the active participation of citizens but, also, and explicitly, on their expertise" (Irwin 2015, 35, italics in original).

Drawing on a participatory health survey I conducted in an industrial area zone near the port of Marseille, France, I will demonstrate how citizen science constructed for policy influence can be made even stronger (Allen et al. 2016). First, working with the residents and local doctors, my team and I developed a health questionnaire. We then randomly and systematically sampled $8.3 \%$ of the households in two of the most pollution-impacted towns. We produced cross-sectional epidemiological data on a myriad of illnesses with prevalence well above comparative national statistics. Our study countered the findings of the French health service (Santé Publique France) that had reported few health issues in this region. Holding dissemination meetings throughout all phases of the project, as well as over 30 focus groups to analyze the data with residents, we produced a health report with the residents. By deeply contextualizing the epidemiology data with the local people, the health study became a more relevant and useful tool for their purposes. The group analysis process enabled citizens to meaningfully interpret the data and align their own analytical assessments with the statistical outcomes. Furthermore, by including their narratives 
of living with illness and pollution as an integral part of the final report, the document became a robust voice for the local population and is currently being used by them successfully to promote environmental change in a variety of ways.

In what follows, I will provide a discussion and rationale for strongly participatory science, particularly expanding on the last phase of this process: analyzing data with local people in focus groups. Using a case study from the Étang de Berre industrial region in France, I will demonstrate how quantitative survey statistics can be effectively linked to qualitative data obtained from interviews and workshops. In conclusion, my study will show that embodied, contextualized knowledge can be a useful tool to amplify citizen voices, thus enabling them to better shape their environments.

\section{Democratization and socially robust knowledge}

When people for whom the science matters are able to participate in its making, this leads to greater contextualization of knowledge. Some science policy scholars have argued that "the more socially robust one's knowledge claims, the more empirically reliable they will be. That is, the more scientific research projects engage with their social environments in egalitarian discussions, the higher the quality of the results of that research" (Harding 2008, 97). I argue that strongly participatory science, science where citizens are more than simply observers or data collectors but are involved in the development of science from start to finish, will be a powerful tool for implementing their choices (Allen 2017, 2018). The strongest science in terms of usefulness and efficacy for local residents is the science that they want to have for answering questions about their environments and their health. This is the knowledge that would enable them to make decisions about their families or pressure policy makers, regulators, and elected officials to do the right thing in the interests of citizens. Thus, social integration of knowledge leads to stronger and more relevant results compared to its weaker version, universal science or socially remote knowledge. Often this kind of science does not speak to laypeople and the ways in which they live and navigate their neighborhoods and places of work. An instructive way to view this is through the lens of environmentally distressed communities. Residents of these places often have many questions, few of which are answered by decontextualized, socially segregated science. Last summer, I met with a member of the scientific council of a major international environmental organization discussing approaches to citizen science. He told me that "we got it wrong" in the past. Trained as a scientist, he explained that the organization thought if you provide the local people with the best natural science produced by unaffiliated or 
unbiased scientists, and you gave that science to the people, they would act. But this did not happen. Citizens given possession of "good environmental science," even by an organization they perceiveed as trustworthy, did not compel action.

Furthermore, other scholars have studied participatory citizen science whereby citizens collect samples of air or water from their environments. The debates with regulatory and corporate officials that ensue over standards of measurement or veracity of data do not necessarily lead to change (Ottinger 2010, 2013; Kinchy 2016). As a scholar of citizen-scientist collaboration for the last two decades, I am interested in what kind of science can serve as "changeagent" knowledge - what are the ingredients that can facilitate action?

My hypothesis, which I tested with a recent project conducted in a polluted French region, is that science that answers the questions that local residents are vociferously asking tended to produce more "action" leading to potential change. While contested communities are often barraged by official data stemming from facility-permitting applications and state regulatory agencies, this data is often in the form of amount of substance released or amount of permissible release, listed substance by substance. Citizens, however, are interested in the total amount of toxic substances impacting their daily lives: home, schools, parks, and other public spaces. But even this data, while concerning, can fail to sufficiently motivate strong civic voices and bring about positive change as defined by the residents, themselves.

I argue that what motivates people living in polluted communities to act are perceived problems with human health - their health and that of their families. While general data about toxins in the environment can elicit concern, evidence of elevated disease and chronic conditions tend to motivate people to speak out and act. This is because one's body provides an intimate and visceral level of empirical knowledge, a kind of "chemical sublime" (Shapiro 2015), as each individual is an expert on their own health and disease experience. Plus, wellness, or lack thereof, has an immediate impact on the day-to-day lives of people, a constant reminder that everything is not all right. Relevant health science is deeply contextualized knowledge, knowledge that I argue can be the impetus to speak out and to act.

\section{Case study and methodology}

Following several years of fieldwork, culminating in a participatory environmental health study, this chapter focuses on addressing the questions of residents in two polluted towns in the Étang de Berre industrial region in France: Fos-sur-Mer (Fos) and Port-Saint-Louis-du-Rhône (PSL) (see Figure 2.1). In 


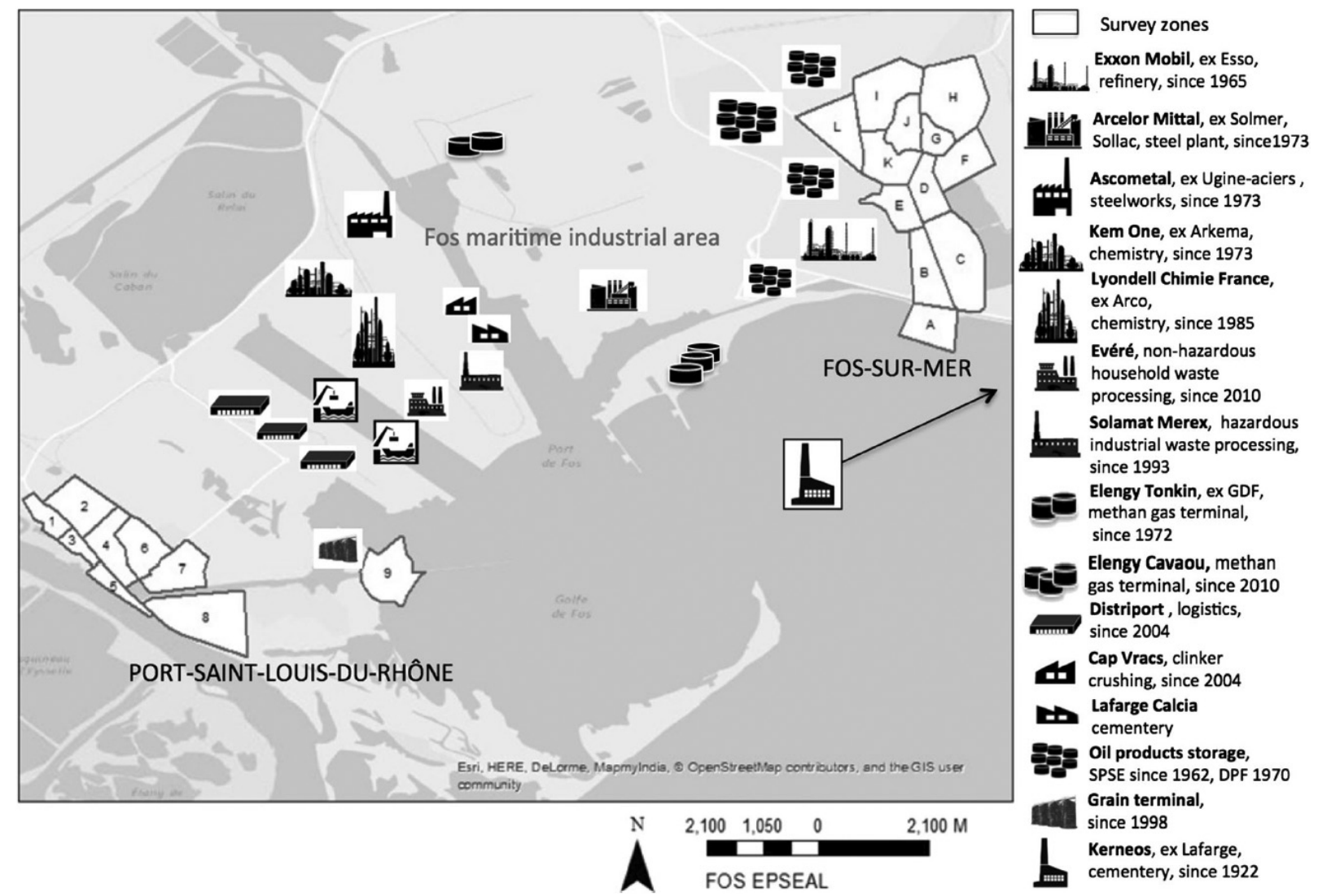

2.1 Map of the region, including zones where the study occurred and locations of industrial activity. 
1965, this area was classified a special development zone of the port of Marseille and all commercial siting decisions were removed from local governments and ceded to a public-private port authority (Garnier 2001). In more recent years, local residents fought against unpopular projects such as the location of a Gaz de France depot on the Fos public beach (opened 2005) and the construction of an incinerator designed to burn all the garbage from the city of Marseille (opened 2010) (Allen 2014). While losing these battles, the disputes raised local awareness about the impacts of industrial pollution, most notably on human health. In response to these concerns, the state conducted over a dozen environmental health and risk studies, all concluding there were few, if any, health problems (Allen et al. 2017b). Many local residents deemed these findings non-credible and attempted creative strategies to obtain health data, from "occupying" the terraces of the French health service building in Marseille and signing petitions, to trying to hack into the service's data repository. Even a local doctor expressed frustration at his inability to obtain data given his concern regarding an inordinate number of chronic illnesses he was seeing in local children.

My interviews with local residents, medical professionals, and government agency officials were part of an earlier NSF-funded project (National Science Foundation) examining how policy-relevant science was shaped in chemical regions. ${ }^{2}$ My idea to conduct a community-based participatory environmental health (CBPEH) survey arose from the concern of my local informants about the lack of relevant health data in their communities. I successfully applied for funding from a new French health agency for environmental and occupational health ${ }^{3}$ to conduct the study and hired Yolaine Ferrier, a local resident of the industrial zone (who had worked with me previously as a translator), as project manager (Allen et al. 2016). Numerous concerned citizens and environmental leaders volunteered to participate in helping with the study and donated space for meetings. Further interviewing local people to be sure we had an exhaustive list of all their health questions, my team epidemiologist, Alison Cohen, designed the health survey tool. ${ }^{4}$ In 2015, we spent six months going door to door, randomly and systematically sampling a cross-section of the population until we had surveyed $8.3 \%$ of the population with a $45 \%$ response rate for those answering the door (Cohen et al. 2017). For illnesses (asthma, cancers, diabetes, etc.) the survey question was phrased: "Have you ever been diagnosed by a doctor with ?" Additionally, we asked questions about chronic conditions that residents had expressed concern about (such as skin conditions, eye irritation, nose and throat irritation, etc.) (see Table 2.1).

In June 2016, we held a series of public meetings in the two towns to disseminate our broad findings about the elevated prevalence of cancer, asthma, diabetes, and other illnesses compared to the French population as a whole. But 
Table 2.1 Health issues in the Fos EPSEAL study and relevant comparison populations. Barbara Allen adapted from Cohen et al. (2017)

\begin{tabular}{lll}
\hline Health outcome & Respondents $(\mathbf{n}=\mathbf{8 1 8})$ & France \\
\hline Self-rated health & $\begin{array}{l}\text { Excellent: } 15 \% \\
\text { Good: } 57 \%\end{array}$ & $\begin{array}{l}\text { Very good: } 25 \% \\
\text { Good: } 43 \%\end{array}$ \\
& $\begin{array}{l}\text { Poor: } 19 \% \\
\text { Very poor: } 7 \%\end{array}$ & $\begin{array}{l}\text { Somewhat good: } 23 \% \\
\text { Very bad: } 1 \%\end{array}$ \\
Chronic conditions & & \\
At least one condition & $63 \%$ & $37 \%$ \\
Chronic skin problems & $26.80 \%$ & $9.40 \%$ \\
Asthma & All: $15.1 \%$ & $10.20 \%$ \\
Cancer & $11.80 \%$ & $4.10 \%$ \\
Endocrine disease (other than & $13.40 \%$ & $5-10 \%$ \\
diabetes) & & \\
Diabetes & $12.9 \%(11.5 \%$ type I,76.9\% & $5 \%(5.6 \%$ type I, 91.9\% \\
& type II, 11.5\% unknown) & type II, 2.5\% unknown) \\
\hline
\end{tabular}

Note: The prevalence of smoking in the French population is $34 \%$ and in our study was $30 \%$. When multiple prevalences are reported, these are from separate studies.

our work making participatory science with the townspeople did not stop with epidemiological statistics. At the public meeting in PSL, a resident and local environmental activist raised his hand and commented, "This data is not us - our lives are not charts and figures." Our work with the citizens to produce rigorous, relevant science was not yet complete. There was a final step, and maybe the most important one, that was yet to come: building a recognizable context in which the data was relevant and had local meaning.

\section{Contextualizing data: from health statistics to residents' science}

Making deeply contextualized science that is empirically strong and valid for communities requires further work on the part of the researcher. Strongly participatory science needs to start from the questions that the local people actually have about their health and their environment, but it must go further than simply producing numeric data and statistics. While relevant data does represent the production of "undone science" in contested places, more needs to happen before the lay population have strong science that can become changeagent knowledge.

Along with a community's quest for science come other effects of the power differential that led to the lack of science in the first place. Often the making of 
science, “... indeed, what comes to count as legitimate knowledge - does not occur on a symmetrical field, but rather in a complex structure of relations of domination and subordination ... [wh]ere dominant scientific cultures define what counts as legitimate knowledge acquisition methods, data, and analysis" (Suryanarayanan and Kleinman 2012: 219, citing Wynne 2003). Typically, the local population had suspicions about illnesses in their community, only to be told otherwise by state officials (Allen 2003, 2014). In the case of France there were no less than a dozen environmental health studies conducted for the benefit of the local residents living in the Étang de Berre industrial region, all showing there was little cause for concern or that there was too much uncertainty in the results such that more studies needed to be done (Allen et al. 2016). There were no studies verifying the illnesses that the local residents and their doctors saw on a regular basis. This gave the citizens a less than clear voice as they tried to explain why they did not trust or believe the studies. The state, over many years, was in effect telling the people that they were imagining or exaggerating their conditions. In a documentary film about health problems in the region, Tumeurs et Silences (2013), an epidemiologist from the regional French health service office in Marseille says, "I've never been to Fos but those reported cancers are hearsay not substantiated facts and figures."

Hermeneutical injustice occurs when there is a collective gap in fully understanding the issues, even when there is an underlying feeling that something is wrong - something that is fully in their interests to make communicable. According to Fricker, "relations of unequal power can skew shared hermeneuti$\mathrm{cal}$ resources so that the powerful tend to have appropriate understandings of their experiences ... [and] the powerless are more likely to find themselves having ... experiences through a glass darkly, with at best ill-fitting meanings to draw on in the effort to render them intelligible" $(2007,148)$. Often the language of science, and more specifically regulatory science, exacerbates the injustice because those who cannot speak that language are left on the outside, looking in to a knowledge arena that they would do well to understand and participate in.

Additionally, for people of color and those in poor and working-class communities, there is the added marginalization of testimonial injustice whereby their experiences and observations about their health and environment are treated as less credible or not relevant in matters of regulation. Both testimonial and hermeneutical injustices have left people searching for a voice with which to represent what they knew empirically but could not really manifest in a way to be heard by policy makers. Years of prejudice in the "economy of credibility" (Fricker 2007, 1) left the residents of the Étang de Berre both frustrated and distrustful of the state, particularly the French health service. The lack of belief 


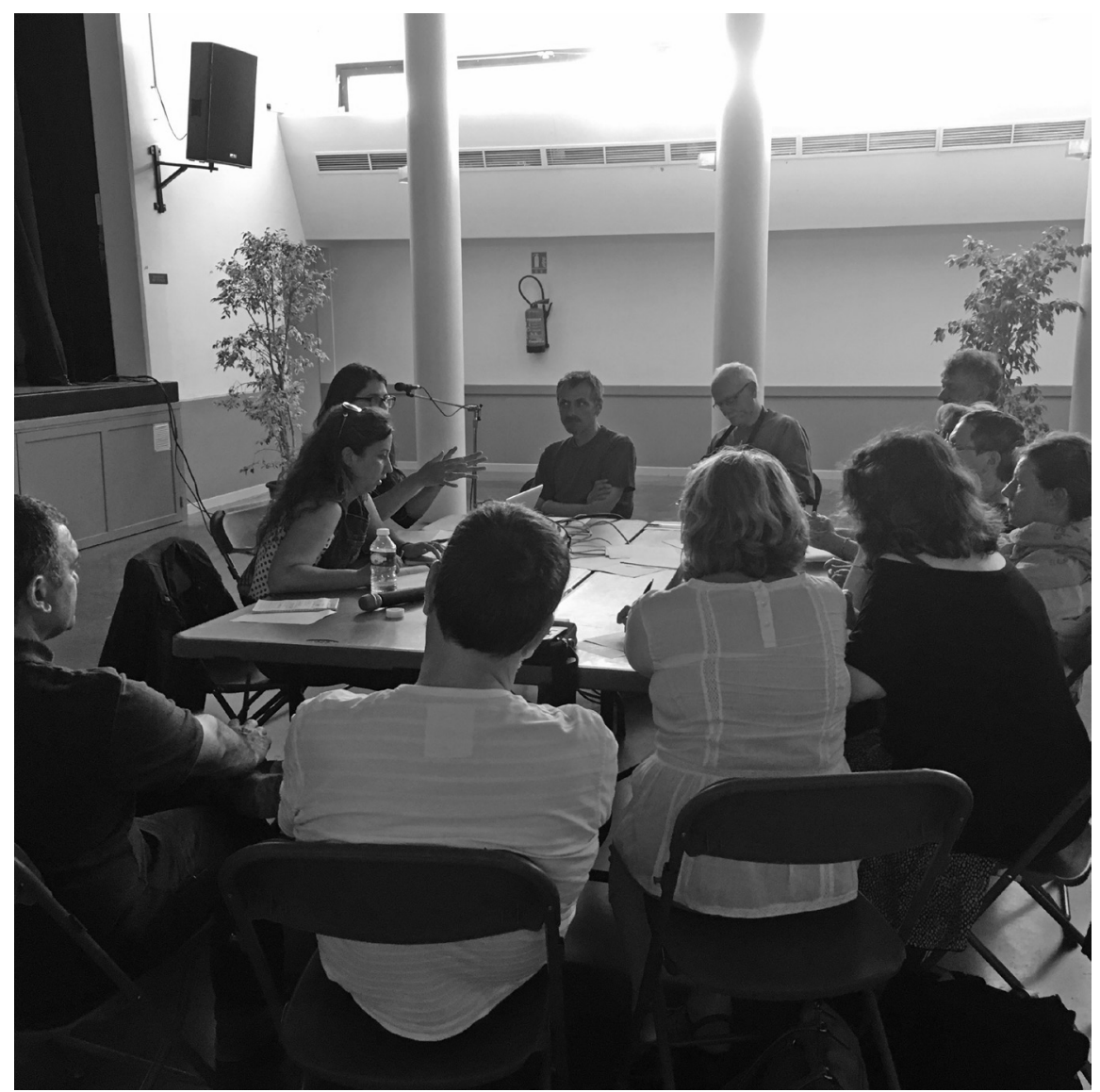

2.2 Residents analyzing data in focus groups.

or willingness to properly investigate on the part of the state left people without words as they were continually told that what they were seeing and saying was not true.

To situate the data in the local context, we held over 30 focus group meetings with five to ten participants over a 10 -week period. These were open, voluntary, and widely advertised in the two towns (Figure 2.2). Given the history of mistrust and lack of credibility of the previous health studies in the region, how we presented the data on the reports was an important discussion item. We wanted their feedback on how best to represent the epidemiological statistics for clarity and understanding. The residents knew from their own experience that people were ill and that their environment was polluted, but their voices were ignored and they were left feeling abandoned. The analyses and grounding 
of the statistics in local experience was one of the main purposes of the focus group discussions. We included quotes from the residents adjacent to the health statistics charts in the relevant sections of the final report. Thus, the relationship of numerical data is clearly aligned with local narratives even to outside readers, policy makers, and the press.

In the case of surprising or contradictory findings, the groups were useful in making sense of confusing data. For example, the discussions provided a lens with which to examine the conceptualization and management of chronic illness and discomfort. The study revealed that $37 \%$ of the French population reported at least one chronic condition, as compared to 63\% of the study's respondents. However, the local residents and the French population's selfreported wellness indicators were about the same with approximately $70 \%$ of both groups reporting their perceived overall health to be between "excellent" and "good." In discussing the statistics, the residents arrived at the idea of the "normalization of illness" in their communities. Further discussion revealed that some residents maintained their perception of "wellness" through prescription medication. One woman remarked that "we are artificially healthy by managing our conditions."

Respiratory issues were common topics for discussion in the focus groups (Figure 2.3 shows the proximity of industry to housing). Asthma in adults was reported in over $15 \%$ of the residents compared to only $10.2 \%$ of the French population. Over $40 \%$ of the adult population and $23 \%$ of the children suffered from at least one form of chronic non-asthma respiratory illness including bronchitis, emphysema, and respiratory allergies not related to hay fever, as compared to $7 \%$ of the French population. This increased prevalence was an issue with the participants, especially given that smoking was somewhat lower than in the French population: $30 \%$ as compared to 34\%. Additionally, $48 \%$ of the respondents with asthma in the study said their disease began in adulthood. This is unusual since asthma begins most often in childhood and, over time, this and related respiratory illnesses are less pronounced in adults (Jacquemin et al. 2015). Discussion among the participants led to their conclusions that air pollution was more likely the culprit. My team would follow up their hypotheses by searching for recent medical publications and would often come back to the participants to confirm their ideas with published studies. In the case of air pollution, my team found that some scientists suggest that atmospheric pollutants have a role in triggering adult-onset asthma (ibid.) Having asthma affected people's daily lives: $28 \%$ of those who reported having asthma missed school or work because of their illness, and 25\% had been hospitalized because of it. In the study, neither income nor education level could account for hospitalization due to asthma, so social disparities was not an explanation. Discussion led to 


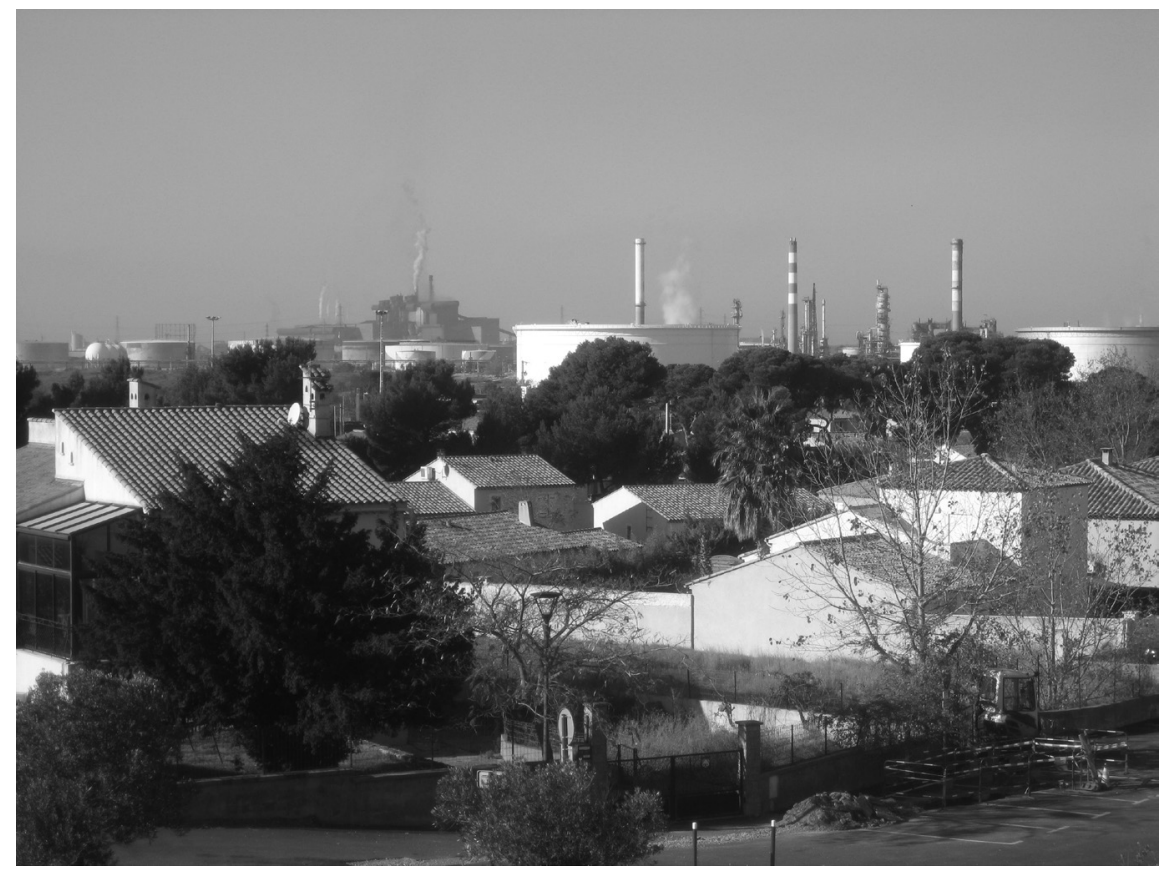

2.3 Homes and industry in Fos-sur-Mer.

the conclusion that hospitalization could be due to the duration and intensity of attacks or in relation to a person's first attack.

A pneumologist from Arles who had once practiced in Port-Saint-Louis expressed interest in, and attended, the local group focused on asthma. She was verbally working out her understanding of the asthma phenomena as she participated in the group discussion:

It is not surprising to find more respiratory diseases in a region where there are factories because there are emissions ... that makes sense ... But there are things I cannot put into words and I thought of coming to your working groups ... What is interesting for me in your study are the nose-throat symptoms, which are not usually listed and I have the impression that in twenty years we will say that they are precursors of certain diseases ...

Participants explained how their bodies and lives are disrupted during "bad air days":

I have been on cortisone for the past fifteen days [when an air alert was in effect] and I could not go out of my house. If the focus group had taken place yesterday, I could 
not have come as there was no wind and it was unbreathable. I get coughing fits in my sleep and am awakened ... sometimes I am afraid as I cannot seem to take a breath. (Asthma group participant)

In July 2015 during an air alert period, I had trouble breathing. It was a crisis for me and the fireman had to come to my house. It was during the holidays ... (Fos-sur-Mer participant)

I have a tingling in my throat and choking sensations at night with difficulties swallowing. It happens at least once a month when there is no wind [to blow the pollution away] ... (Fos-sur-Mer participant)

Children's sports and personal exercise habits were topics of discussion around air pollution. One mother described her son, who did not have asthma but who experienced breathing difficulties and "whistles" when playing soccer on a field directly adjacent to industrial sites:

Are refineries not able to adjust their off-gassing to not coincide with children's soccer schedules and off-gas only on windy days? Basically, I think the plants off-gas according to performance requirements, and not according to the weather ... The football field, with brand new synthetic turf, is right on the trajectory of the smoke. Could they not have found a better place in town to practice football? (Fos-sur-Mer participant)

The impossible cohabitation between outdoor exercise and industrial practices was a point of frustration and adaptation. A cyclist mentioned that he puts his bike in his car and begins his touring 20 to 30 kilometers north of the city. A jogger noted that on cloudy days it is more difficult to breathe at the end of his usual loop than in clear weather. Explains another Port-Saint-Louis participant: "We are advised not to do too much sport when it is polluted, but it is hard to live that way."

There are also other ways that the townspeople dealt with the heavy load of pollutants on their bodies. Numerous participants mentioned going to cleaner environments for vacations as much as possible - and noted how well they could breathe and how much better they felt when they came back. One participant said (echoing others), "We go twice a year for two weeks in the Pyrenees, and twice a year for two weeks in the southwest too - we go there to breathe." Another respondent explained that "we have to go to the mountains and when we're there, it's better, and we breathe - and as soon as we come back here, we feel the difference."

The view of many participants was that particularly noxious releases happened at night: 
The first year here I thought I'd go crazy at night, with the noise of factories that does not stop for a moment. Sometimes I wear earplugs. I wake up always tired in the morning. (A resident recently settled in Fos-sur-Mer)

Yesterday I returned at four-o'clock in the morning and it was fireworks. The plants were flaring as when they have to release more pollution ... and I do not know why it happens so often at night. Yesterday it was at Esso, spitting out from everywhere and we could see these smoke clouds. (Port-Saint-Louis participant)

The representative of Air PACA (the air monitoring association) indicated that the factories are operated on a continual basis, around the clock, for economic reasons. However, some residents mentioned feeling greater effects of pollution at night, when their windows were open or when they were outside. This local belief could be because in calm weather the pollution stagnates closer to the ground, which is cooler at night. The increased visibility of the flares at night also reinforces the belief about more flaring after dark, thus bolstering the distrust the citizens feel about industry.

Cancer was another common topic among participants trying to make sense of the health data. While the prevalence of cancer in the towns was $11.8 \% \mathrm{com}-$ pared to $4.1 \%$ for the French population, it was much higher for women (14.5\%) as compared to men $(8.3 \%)$ in our study. Furthermore, while the most common cancers in the living population in France were breast, prostate, and colon, in our study uterine cancer was in third place, displacing colon cancer in prevalence. The residents and local doctors in our groups discussed this alarming data:

Of course the uterus should not be there as normally gynecological cancers are further down in the rankings ... so it is striking to see the uterus as it is a serious disease ... and one dies from it. (Oncologist participant in the cancer focus group)

Our workshop leaders checked and confirmed what the oncologist had said: cancer of the uterus is serious as the 10-year survival rate is estimated at $68 \%$ (Grosclaude et al. 2013, 4). Another doctor in the group mentioned the possibility that uterine cancer may have even been under-reported as women having hysterectomies did not always report a cancer, which may have been present, or have developed later. Participants discussed the endocrine-disrupting nature of some of the polluting chemicals as a possible reason for elevated cancers in hormone-dependent areas of the body, noting that thyroid cancer was also elevated. Other ideas that emerged were that women's cancers (such as breast cancer) generally have a good prognosis and can be managed over time and survived. They also hypothesized that women were more likely to seek treatment early and be vigilant in their medical regimes. 
Noting the absence of certain cancers with poor prognoses (i.e., lung and pancreas), focus group participants wondered whether men might be more impacted by these diseases. We explained that their absence does not mean that they do not exist, but that either our numbers were too low for inclusion (i.e., fewer than 10 cases for privacy and statistical reasons) or that people with these illnesses were too sick to answer our survey. The two Fos EPSEAL (Étude participative en santé environnement ancrée localement sur le front industriel de Fos-sur-Mer et Port-Saint-Louis-du-Rhône) team members relayed to the participants that at least once a day while they were collecting the door-to-door surveys someone would respond, "I am too ill to speak with you," or "It's too difficult to talk as my husband is in the middle of dealing with cancer," or, "Thank you mademoiselle, but I am seriously ill and do not want to talk about it." We explained to the participants that mortality studies are often better at capturing the prevalence of fast-acting cancers.

Another anomaly in the study was that $15 \%$ of residents who reported having cancer also reported having or having had more than one type of cancer (two to four cancers per person). A cumulative number of cancers in the same person can sometimes happen, but the doctors, including an oncologist, in our groups felt that the frequency of this phenomenon in the study, as well as the nature of the associated cancer sites, seemed atypical. Dr. Vincent Besin, a recently retired local physician in Port-Saint-Louis who attended some of the focus groups, explained his professional view in an earlier interview:

\footnotetext{
You have different stages of illness in this area. First, are the immunological diseases (lupus, vascularites/phlebitis, skin disease, respiratory illness, chronic bronchitis) followed by cancers such as immunological cancers, and then sarcomas of the lung, lymph, and different kinds of pharynx/throat cancers. Finally, in some cases, the same person has a multiple cancers and/or cardiac disease or attacks. My wife (also a local physician) and I consider that there are three stages in time for a pathology here, on a period of twenty years: (1) small incidents stage; (2) strange disease stage where it looks like the disease you've studied in text books, but with always a little difference; and (3) catastrophic stage with cancers, strokes. ${ }^{5}$
}

Some of the groups focused on particular neighborhoods where residents wanted to better understand the data in context. At the beginning of our health survey, there were a number of residents in Fos-sur-Mer who had told us they thought the Carabins neighborhood had more serious health problems, specifically cancer, than the rest of the town (see Figure 2.1; Carabins delineated by area I and J). In order to collect neighborhood-specific data during the collection phase of our project, each town was divided into a grid, such that health outcomes could be assessed by zone. Our survey data did show that the Carabins 
neighborhood had nearly double the cancer prevalence than Fos-sur-Mer and Port-Saint-Louis, which themselves had almost double the cancer prevalence of the French population. This was discussed in the groups with the goal of trying to better understand this negative health outcome. First, our team ruled out socioeconomic disparities as this neighborhood was the least economically depressed in our study with only $4 \%$ of the population living in poverty as compared to $20 \%$ in Port-Saint-Louis or $10 \%$ in Fos-sur-Mer. Additionally, the number of Carabins residents exposed to industrial pollution in their current jobs is lower than the study average and about the same as the other two towns in previous employment, thus occupational exposure is not an explanation on the face of it. However, the residents' reflection on the history of the neighborhood yielded some possible explanations. People recalled that many men from this neighborhood worked in the steel plant, spending hours in very demanding locations such as the coking plant, the blast furnaces, and welding. This was also one of the least transient neighborhoods in Fos-sur-Mer, with residents living there 25 years, on average. According to one resident of that area:

It's true that in the neighborhood there was a lot of illness. One of our neighbors had two sons both die of cancer at about thirty years old. One had a brain tumor, the other I don't know. On our street there were other brain tumors ... I do not know if it's a coincidence, but it's true in our neighborhood that a lot of cancer exists and it really worries us.

The groups' last hypothesis was the location of the Carabins neighborhood relative to air pollutants as, regardless of which way the wind was blowing, the area was engulfed in a toxic plume. A scientist from Air PACA attended one of the focus groups and expressed doubts about differentiated air quality within the zone. He first said that the air pollutants impacting the zones were more or less homogeneous. However, during a discussion with the residents he acknowledged that the exposure profile to air pollutants was more clearly industrial in Fos, with a particular cumulative exposure to pollutants in the air of the Carabins neighborhood.

Reflexively speaking, some group participants questioned whether meeting to share stories about chronic illness was advised. One woman said that she felt she might be ill and the discussion groups made her more worried. Other residents expressed concern that our focus group meetings could further normalize their pathologies and thus make complaints banal or citizens less inclined to take action. Others felt that the normalization of illness could be seen as a form of resilience in that they perceive themselves as living well and closer to nature compared to their urban counterparts. 
People also wanted more reliable and accurate information, with sources considered legitimate locally, about the possible impacts of their environment on their health. The inhabitants were conscious of living in a specific environment that required a more detailed and contextualized attention, particularly in view of the power asymmetry of the forces involved. The lack of intellectual honesty of the industrialists in their communication with the inhabitants engendered a climate of distrust that sustained local controversies and suspicions:

You have to have data to know what you are talking about ... except perhaps to challenge the visual observations ... When I was working at Sollac, I expressed my opinion to my colleagues, on the $\mathrm{pH}$ levels of the water in the basin, because of the color ... Well I was right, they had to re-calibrate the device that had made a wrong measurement ... Also what astonishes me in Fos is the Blue Flag! [referring to the public air quality alert system, blue indicating the air is clean] (Fos-sur-Mer participant and retired industrial worker)

\section{Discussion}

Lack of representation of the local people in earlier studies conducted by the state served to "misframe" the health issues of the population and, thus, "misrecognize" the problems the citizens had been trying to convey, leading to a sense of environmental injustice (Fraser 2010). This led to a deep mistrust among citizens of the French health service since they were treated as if their voices did not matter when it came to their own health - a testimonial injustice. Given that trust and credibility are relational, the exclusionary protocols and behavior of the state agents all but ensured a negative rapport with local citizens (Wynne 1992).

While our project also collected data about health, unlike the state, we started with local health questions to build a participatory survey and rigorous epidemiology data. This was a "scientized" response to the many state studies that showed little or no evidence of increased illness in the region. This approach has potential pitfalls. On a cautionary note, explain Kimura and Kinchy (2016, 349): "In a context where regulatory agencies will only respond to scientific data, rather than in a community's widely-held knowledge of environmental illness, it may be necessary to present grievances in the form of scientific data, but this devalues the knowledge of non-scientists and minimizes questions of social justice." I argue, however, that the knowledge of laypersons can be embedded in the kinds of statistical data that are policy ready. Situated science, knowledge inclusive of the lay public's voice, can become an incredible tool for shaping local and even national environments. 
The key to hybridizing data is collaborative analysis. In our project, the linking of quantitative to qualitative data has increased the relevance of the study results to both residents and local medical professionals. The participants in the analysis workshops discussed the data, making sense of the numbers from their perspective. All of the quotations from residents and local doctors in the preceding section were included in the final 72-page report for our health survey, called Fos EPSEAL (Allen et al. 2017a). In the various sections divided by illness type, these stories and hypotheses of the local residents and medical professionals were presented side by side with the statistical data. This served, in the report, to structurally align the qualitative data with its quantitative counterpart, engendering greater interpretive representativeness and thus ownership of the study by the citizens.

The final report was presented to the residents and then to a large public audience in Marseille in January 2017 and the data published soon after (Allen et al. 2017a; Cohen et al. 2017). Immediately after, the report was available online and received a lot of attention from the local and national media over the course of the next year. Within months, there had been over 100 newspaper/magazine articles, medical journal discussions, radio programs, and television reports about the health outcomes revealed by the Fos EPSEAL study. The coverage often featured several local residents and doctors speaking authoritatively about their local health issues, using the study as evidence. The media buzz also generated numerous requests from other polluted towns in France, wanting a similar study. Generally, these towns were also the beneficiaries of official government health studies telling them that little or nothing was wrong with them even though, like Fos and PSL, they had empirical evidence that told them otherwise.

The French health service was contacted by the press after the release of our study. They were asked to comment on why their multiple studies did not align with ours and instead revealed few, if any, health problems in the region. Their response was to conduct an evaluation of our study and methodology, releasing it in early 2018 (Rapport 2018). Their rhetoric when speaking publicly about the project was to frame our project as "opinions" or "perceptions" of the residents. We continually corrected them by explaining that we were measuring prevalence of illness based on self-reporting and emphasized that many of our questions began with, "Have you ever been diagnosed by a doctor with ...?"

In the end, the French health service report was mostly positive and their main disagreements with our study - the representativeness of the sample, the indicators used, and the types of data standardization - were, according to our team epidemiologist, typical disagreements within the field itself. However, one of their critiques of something very important to our methodology caught our attention. The health service stated that: 
After data collection, the quantitative results of the study were discussed with the local people. In drafting the report, to ensure a clear presentation, a rigorous structuring separating the statistical results from their local interpretation is necessary. (Rapport 2018, 16)

In a meeting we had with the French health service, following their report, they reiterated their displeasure that our Fos EPSEAL report presented the health outcomes data alongside the residents' interpretation of that data including their hypotheses regarding causation. ${ }^{6}$ However, their report continues:

The effort and resources devoted to the discussion of the final results with the population is a strong point of the Fos EPSEAL study ... The explanatory hypotheses put forward by the inhabitants was analyzed with the disciplinary knowledge of the medical professionals invited to the focus groups, in order to refine them ... The purpose of these discussions was to increase the impact of results, particularly in local decisionmaking, engaging the community ... (Rapport 2018, 18)

Though the health service had some typical disciplinary disagreements with our study, they realized that the hybridization of data, even though it made them uncomfortable, was the actual strength of the Fos EPSEAL study. Following the initial study, we hosted an ANSES-funded training workshop to teach 25 French scholars and health professionals how to conduct a CBPEH survey similar to ours. Several professionals from the French health service enrolled. Additionally, following a presentation of our project's participatory approach at the French health service's 2018 "Public Health Days," one of their lead epidemiologists asked if we would be willing to lead a similar training for them, which is a positive sign for the future of this resident-inclusive methodology at the institutional level in France. In a final meeting between my team and a group of French health service officials, they said that while a "declarative" study such as ours could be complementary to their work, it did not supplant their own studies from "medico-administrative data."

\section{Conclusion}

Since the study was released, it has been used in a number of important ways to pressure for positive change. Mayor Renaudi of Fos has used the survey to try to stop the expansion of the incinerator that burns all the garbage from the city of Marseille. In a letter to Mayor Gaudin of Marseille, the second largest city in France, Renaudi states: "We have data." Additionally, politicians of PSL have used the study to try to stop excess release permits by industry. Doctors 
of the nearby hospital have applied for funding to study some of the connections between health outcomes uncovered by the Fos EPSEAL study. At the end of every focus group we asked the participants to come up with "next steps" now that they have the data they have been wanting. They came up with dozens of ideas, including better air quality warning systems, indoor play facilities for schools, local access to medical specialists, better public transportation to discourage auto traffic, and dissemination of recommendations and "best practices" for local food consumption. Other ideas for city administrators were suggested, such as ending mechanical blowing for street cleaning, reducing pesticide spraying for mosquitos, and adding charging stations to promote electric cars. The townspeople were energized and, in 2018, seven citizen groups, several workers' unions, and 260 citizens filed both civil and criminal lawsuits against the state and industry for endangering their health - a first in France (Nossiter 2020).

In thinking about the transferability of this epidemiology-based, strongly participatory approach to other sites, nationally and internationally, both difficulties and potentials come to mind. One of the criticisms of our study from the regional prefecture, faced with citizen groups wanting a similar health study, was its cost, approximately €200,000. This included door-to-door surveying done by post-docs as well as a US-based epidemiologist and project director. The cost could be lowered by having volunteer or student surveyors and only hiring graduate students or post-docs to run the focus groups. Additionally, having locally based epidemiologists and project directors would decrease travel costs. There is also the issue of funding sources, as even if the cost could be cut in half, it is still prohibitive for many communities.

Another barrier to transferability of this kind of study is the way in which the questions were asked. We ascertained illness prevalence by asking residents if they had been so diagnosed by a doctor. In countries such as the United States and developing nations, where healthcare may not be available to everyone, questions would have to be framed differently, possibly expanded to capture symptoms and chronic conditions. While there is clearly work to be done in developing an approach that is accessible to vulnerable communities worldwide, there is some additional promise to consider. Often, communities exposed to industrial pollution witness a number of rare diseases, such as pediatric cancer, that are hard to assess with anecdotal (e.g., disease clusters) or statistical tools given their small numbers. However, with a non-state controlled participatory study, health outcomes data could be aggregated across inhabited areas with similar pollutant exposures in multiple countries producing statistically significant results. This has the potential of showing correlations between specific illnesses and particular pollutants, something that single site studies typically cannot reveal. 
In conclusion, the public, such as residents in polluted communities, have salient knowledge about their health and environment that needs to be taken seriously. This is important knowledge-in-context, health seen from the perspective of those that live it daily. If the only people who are allowed to be experts of people's health are people sitting in offices far from the polluted towns and sites, and if the "disembodied" science that they create is the only measure of health, then we do not have a robust health outcome picture. Furthermore, if only outside experts with political power and authority get to define the health and environmental issues to be addressed and select the terms of deliberation, then democracy has not been well served. However, in making the case for "knowledge democracy" (Marres 2018a) or "knowledge justice" (Allen 2018) today we must be clear that we are not aligning with anti-science or antiintellectual viewpoints evident on the political right. Expanding the realm of expertise to include embodied public knowledge, specifically what residents of environmentally degraded environments observe on a daily basis, strengthens science. Broadening what can be known about the places that we live in beyond the authority of experts, to further empirical public validation, is not playing into deception and demagoguery of populism and post-truth politics (Hoffman 2018). Instead, as the Fos EPSEAL project has demonstrated, the robust inclusion of local people in the making of environmental health science - from the questions asked to the in-depth collaborative analyses of the data collected leads to more relevant and effective science in contested regions.

Funding note: This research was supported the Agence Nationale de Sécurité Sanitaire de l'alimentation, de l'environnement et du travail (ANSES) (award number: PNREST Anses, Cancer ITMO AVIESAN, 2014/1/023 and EST/2017/1/035), and also received support from the Institut Méditerranéen de Recherches Avancées (IMéRA) in Marseille, France.

\section{Notes}

1 Strong objectivity is about transparency and inclusiveness in the making of scientific knowledge. On one hand, it is about including the observations and hypotheses of diverse stakeholders in the shaping of science, and on the other hand, it is about revealing voices and interests that have been hidden from view in traditional science, also termed by Harding (2015) "weakly objective science."

2 During this project, I conducted over 45 semi-structured interviews focusing on citizen inclusion or exclusion in the environmental policy process. Written consent was obtained where names are used, and the interviews were transcribed and translated into English. 
3 ANSES (Agence Nationale de Sécurité Sanitaire de l'Alimentation, de l'Environnement, et du Travail) is a relatively new French agency for food, environmental, and occupational health.

4 Alison Cohen was at the time a doctoral candidate in epidemiology at the University of California, Berkeley. She had experience in designing and conducting CBPEH studies in polluted communities in California (Cohen et al. 2012).

5 Vincent Besin, retired physician, interviewed by Barbara Allen and Yolaine Ferrier (translator), in Port-Saint-Louis-du-Rhône, December 9, 2013.

6 Our process with regard to the local participants' theories of disease causation or correlation was to follow up by searching in the peer-reviewed literature for studies verifying their ideas. Oftentimes we found such studies and brought them back to the focus groups in subsequent meetings. We also invited medical specialists to our group meetings and they hypothesized with the residents, adding their opinions where appropriate.

7 From distance meeting with Santé Publique France, March 21, 2018.

\section{References}

Allen, B. 2003. Uneasy Alchemy: Citizens and Experts in Louisiana's Chemical Corridor Disputes. Cambridge, MA: MIT Press.

Allen, B. 2014. The social construction of non-knowledge. Perspectives: Journal Réseau français des Instituts détudes avancées, 12(Winter), 9. Available at http://rfiea.fr/articles/socialconstruction-non-knowledge (last accessed January 23, 2020).

Allen, B. 2017. A successful experiment in participatory science for promoting change in a french industrial region. Engaging Science, Technology, and Society, 3, 375-381.

Allen, B. 2018. Strongly participatory science and knowledge justice in an environmentally contested region. Science, Technology and Human Values, 1-25. DOI: 10.1177/0162243918758380.

Allen, B., Cohen, A., Ferrier, Y., Lees, J., and Richards, T. 2016. Redesigning a participatory health study for French industrial context. New Solutions: A Journal of Environmental and Occupational Health Policy, 26(3), 458-474.

Allen, B., Cohen, A., Ferrier, Y., and Lees, J. 2017a. FOS EPSEAL: Etude participative en santé environnement ancrée localement sur le front industriel de Fos-sur-Mer et Port-Saint-Louis-duRhône. Available at https://fosepseal.hypotheses.org/rapport-de-letude-fos-epsealjanvier-2017 (last accessed January 23, 2020).

Allen, B., Ferrier, Y., and Cohen, A. 2017b. Through a maze of studies: Health questions and "undone science" in a French industrial region. Environmental Sociology, 3(2), 134-144.

Cohen, A., Lopez, A., Malloy, N., et al. 2012. Our environment, our health: A communitybased participatory environmental health survey in Richmond, California. Health Education \& Behavior, 39(2), 198-209.

Cohen, A., Richards, T., Allen, B., Ferrier, Y., Lees, J., and Smith, L. 2017. Health issues in the industrial port zone of Marseille, France: The Fos EPSEAL 
community-based cross-sectional survey. Journal of Public Health, 26(2), 235-243. DOI: $10.1007 / \mathrm{s} 10389-017-0857-5$.

Fraser, N. 2010. Scales of Justice: Reimagining Political Space in a Globalizing World. New York: Columbia University Press.

Fricker, M. 2007. Epistemic Injustice: Power and the Ethics of Knowing. Oxford: Oxford University Press.

Garnier, J. 2001. L'évolution du complexe industriel de Fos/Lavéra/Etang de Berre. Aix-enProvence: Laboratoire d'Economie et de Sociologie du Travail, CNRS.

Grosclaude, P., et al. 2013. Survie des personnes atteintes de cancer en France, 1989-2007. Etude à partir des registres des cancers du réseau Francim. Synthèse, Institut national de Veille Sanitaire, Paris: Santé Publique France.

Haklay, M. 2013. Citizen science and volunteered geographic information: Overview and typology of participation. In D. Sui, S. Elwood, and M. Goodchild (eds), Crowdsourcing Geographic Knowledge. New York: Springer, pp. 105-122.

Harding, S. 1991. Whose Science? Whose Knowledge?: Thinking from Women's Lives. Ithaca, NY: Cornell University Press.

Harding, S. 2008. Sciences from Below: Feminisms, Postcolonialities, and Modernities. Durham, NC: Duke University Press.

Harding, S. 2015. Objectivity and Diversity: Another Logic of Scientific Research. Chicago: University of Chicago Press.

Hess, D. 2007. Alternative Pathways in Science and Industry: Activism, Innovation, and the Environment in an Era of Globalization. Cambridge, MA: MIT Press.

Hess, D. 2015. Undone science and social movements: A review and typology. In M. Gross and L. McGoey (eds), Routledge International Handbook of Ignorance Studies. New York: Routledge, pp. 141-154.

Hess, D., Sulfikar, A., Frickel, S., Kleinman, D., Moore, K., and Williams, L. 2017. Structural inequality and the politics of science and technology. In U. Felt, R. Fouché, C. Miller, and L. Smith-Doerr (eds), Handbook of Science and Technology Studies. Cambridge, MA: MIT Press, pp. 319-347.

Hoffman, S. 2018. The responsibilities and obligations of STS in a moment of post-truth demagoguery. Engaging Science, Technology, and Society, 4, 444-452.

Irwin, A. 2015. Citizen science and scientific citizenship: same words, different meanings? In B. Schiele, J. Marec, and P. Baranger (eds), Science Communication Today. Nancy: Presses Universitaires de Nancy, pp. 29-38.

Jacquemin, B., et al. 2015. Ambient air pollution and adult asthma incidence in six European cohorts (ESCAPE). Environmental Health Perspectives, 123(6), 613-621.

Kimura, A. and Kinchy, A. 2016. Citizen science: Probing the virtues and contexts of participatory research. Engaging Science, Technology, and Society, 2, 331-361.

Kinchy, A. 2016. Citizen science and democracy: Participatory water monitoring in the Marcellus shale fracking boom. Science as Culture. DOI: 10.1080/09505431.2016. 1223113.

Marres, N. 2018a. Why we can't have our facts back. Engaging Science, Technology, and Society, 4, 423-443. 
Marres, N. 2018b."Response to Steven Hoffman's “The Responsibilities and Obligations of STS in a Moment of Post-Truth Demagoguery”. Engaging Science, Technology, and Society, 4, 453-457.

Moore, K., Hess, D., Kleinman, D., and Frickel, S. 2011. Science and Neoliberal Globalization. Theory and Society, 40, 505-532.

Nossiter, A. 2020. "One of Europe's Most Polluted Towns Stages a Noisy Revolt”. New York Times, April 1. https://www.nytimes.com/2020/04/01/world/europe/francepollution-fos-sur-mer.html (last accessed May 1, 2020).

Ottinger, G. 2010. Buckets of resistance: Standards and the effectiveness of citizen science. Science, Technology \& Human Values, 35(2), 244-270. DOI: 10.1177/01622439093371 21.

Ottinger, G. 2013. Refining Expertise: How Responsible Engineers Subvert Environmental Justice Challenges. New York: NYU Press.

Rapport d'analyse de l'etude Fos-EPSEAL. 2018. Saisine No. 17-DSPE-0217-1513-D. SaintMaurice: Santé Publique France. http://invs.santepubliquefrance.fr/Publications-etoutils / Rapports-et-syntheses / Environnement-et-sante/2018/Rapport-d-analyse-del-etude-Fos-Epseal (last accessed January 24, 2020).

Shapiro, N. 2015. Attuning to the chemosphere: Domestic formaldehyde, bodily reasoning, and the chemical sublime. Cultural Anthropology, 30(3), 368-393.

Sismondo, S. 2017. Post-truth? Social Studies of Science, 47(1), 3-6.

Suryanarayanan, S. and Kleinman, D. 2012. B(e)ecoming experts: The controversy over insecticides in the honey bee colony collapse disorder. Social Studies of Science, 43(2), 215-240.

Winderberger, J. 2013. Tumeurs et Silences (film).

Wynne, B. 1992. Misunderstood misunderstanding: social identities and public uptake of science. Public Understanding of Science, 1(3), 281-304. 